\title{
Medical Student Training in eHealth: Scoping Review
}

Jean-François Echelard $^{1}$, MD; François Méthot ${ }^{1 *}$, BBA; Hue-Anh Nguyen ${ }^{1^{*}}$, MD; Marie-Pascale Pomey ${ }^{2,3,4}$, MD, $\mathrm{PhD}$

\footnotetext{
${ }^{1}$ Faculty of Medicine, Université de Montréal, Montréal, QC, Canada

${ }^{2}$ Research Centre, University of Montreal Hospital Center, Montreal, QC, Canada, University of Montreal Hospital Center, Montreal, QC, Canada

${ }^{3}$ Department of Management, Evaluation and Health Policy, School of Public Health, Université de Montréal, Montreal, QC, Canada

${ }^{4}$ Department of Family Medicine and Emergency Medicine, Faculty of Medicine, Université de Montréal, Montreal, QC, Canada

* these authors contributed equally
}

\section{Corresponding Author:}

Jean-François Echelard, MD

Faculty of Medicine

Université de Montréal

2900 Edouard Montpetit Blvd

Montréal, QC, H3T 1J4

Canada

Phone: 15143436111

Email: jfechelard@ hotmail.com

\section{Abstract}

Background: eHealth is the use of information and communication technologies to enable and improve health and health care services. It is crucial that medical students receive adequate training in eHealth as they will work in clinical environments that are increasingly being enabled by technology. This trend is especially accelerated by the COVID-19 pandemic as it complicates traditional face-to-face medical consultations and highlights the need for innovative approaches in health care.

Objective: This review aims to evaluate the extent and nature of the existing literature on medical student training in eHealth. In detail, it aims to examine what this education consists of, the barriers, enhancing factors, and propositions for improving the medical curriculum. This review focuses primarily on some key technologies such as mobile health (mHealth), the internet of things (IoT), telehealth, and artificial intelligence (AI).

Methods: Searches were performed on 4 databases, and articles were selected based on the eligibility criteria. Studies had to be related to the training of medical students in eHealth. The eligibility criteria were studies published since 2014 , from a peer-reviewed journal, and written in either English or French. A grid was used to extract and chart data.

Results: The search resulted in 25 articles. The most studied aspect was mHealth. eHealth as a broad concept, the IoT, AI, and programming were least covered. A total of 52\% (13/25) of all studies contained an intervention, mostly regarding mHealth, electronic health records, web-based medical resources, and programming. The findings included various barriers, enhancing factors, and propositions for improving the medical curriculum.

Conclusions: Trends have emerged regarding the suboptimal present state of eHealth training and barriers, enhancing factors, and propositions for optimal training. We recommend that additional studies be conducted on the following themes: barriers, enhancing factors, propositions for optimal training, competencies that medical students should acquire, learning outcomes from eHealth training, and patient care outcomes from this training. Additional studies should be conducted on eHealth and each of its aspects, especially on the IoT, AI, programming, and eHealth as a broad concept. Training in eHealth is critical to medical practice in clinical environments that are increasingly being enabled by technology. The need for innovative approaches in health care during the COVID-19 pandemic further highlights the relevance of this training.

(JMIR Med Educ 2020;6(2):e20027) doi: 10.2196/20027

\section{KEYWORDS}

medical education; eHealth; digital health; mHealth; health apps; telehealth; artificial intelligence; electronic health records; programming; internet of things 


\section{Introduction}

\section{Background}

In 2018, a survey by the Canadian Medical Association showed that approximately " $75 \%$ of Canadians believe new technologies could solve existing issues in [the] health care system" [1]. In reality, such technologies are continually being developed to address health care needs in diverse fields. For instance, remote medical interventions can enable access to health care in rural areas as well as support diabetes management [2,3]. Medical mobile apps can enhance asthma management [4]. Artificial intelligence (AI) can measure cancer risk or predict mental health outcomes $[5,6]$. The concept that is defined by the use of such technologies in health care is termed eHealth [7]. As the COVID-19 pandemic challenges health care systems worldwide, eHealth technologies enable physicians to continue to provide medical consultations while maintaining social distancing. In this context, clinicians must "conduct more virtual consultations than before, while uncertain about how to do so effectively." This crisis also highlights the need for innovative approaches in health care [8]. eHealth encompasses many technologies and is not limited to remote medical interventions.

\section{Defining eHealth}

Various definitions of eHealth have been proposed by many authors during the last two decades. The definitions vary in breadth, ranging from being vague to highly specific. According to recent definitions that could be deemed either too broad or too narrow, eHealth is the use of information and communication technologies to enable and improve health and health care services [9]. Various technologies fit into this definition when they are applied to health. This is notably the case for AI, telemedicine, the internet of things (IoT), connected devices, and mobile health (mHealth). Although some may consider the following technologies as part of eHealth, the scope of our definition does not include 3D printing, robotics, blockchain, and nanotechnology. Important terms regarding eHealth are defined in Multimedia Appendix 1.

\section{Strategic Approaches to eHealth}

National eHealth strategies have been adopted by various countries, including Australia in 2008 and France in 2016 [10,11]. The World Health Organization also published a national eHealth strategy toolkit in 2012 [12]. According to the aforementioned eHealth strategies, adequate workforce education and training are required and may depend upon "development, integration or changes to existing curricula." In the same spirit, in 2014, Canada developed a set of eHealth competencies for undergraduate medical education, acknowledging that medical students have to be better prepared "to practice in modern, technology-enabled, clinical environments" [9]. Although such initiatives clearly indicate that there is a need to train the next generation of physicians for future medical practice, it is relevant to examine the education that medical students are actually getting regarding eHealth and how this training is perceived. The literature on this topic is heterogeneous and has not yet been comprehensively reviewed.

\section{Goal of This Study}

This review aims to evaluate the extent and nature of the existing literature on medical student training in eHealth worldwide. More precisely, we approached this study with the following research questions: (1) to what extent and how are medical students being educated about eHealth and (2) what are the barriers, enhancing factors, and propositions regarding this training? This review focuses primarily on some key technologies under the umbrella of eHealth, namely mHealth, the IoT, telehealth, and AI.

\section{Methods}

\section{Theoretical Framework}

We followed the 5-stage framework by Arksey and O'Malley in conducting this scoping review: identifying the research question, identifying relevant studies, screening studies, charting the data, and collating, summarizing, and reporting the results [13]. We also followed guidelines from the PRISMA-ScR (Preferred Reporting Items for Systematic Reviews and Meta-Analyses Extension for Scoping Reviews).

\section{Identifying the Research Question}

As described earlier, this review's primary focus is to map the literature on medical student training in eHealth, given the continuous development of eHealth technologies in medicine and the importance of adequate education for doctors who will have to work in such an environment. Given the breadth of eHealth, the scope of this review has been narrowed to some key technologies under the umbrella of eHealth; therefore, mHealth, the IoT, telehealth, and AI are the primary focus of this review. However, other technologies directly relevant to the research question are deemed to be of interest for this review.

\section{Identifying Relevant Studies}

A systematic literature search was performed in 4 medical databases (Cochrane Library, MEDLINE [Medical Literature Analysis and Retrieval System Online], Web of Sciences, and the Journal of Medical Internet Research [JMIR]: Medical Education) using keywords developed through a preliminary search on the review topic. The databases were selected based on their broad spectrum of results, specificity for peer-reviewed articles, and relevance for medical topics. The preliminary search on these databases yielded relevant articles, and these databases were therefore deemed adequate. Similarly, no search for gray literature was done because the scope of this review did not extend to articles that had not been peer reviewed. The keywords were selected to gather results about medical student training in eHealth as a broad concept, and some were specifically added to increase sensitivity for articles regarding AI, the IoT, and mobile apps. Increasing sensitivity for these technologies was considered congruent with the primary focus of this review on a subset of key technologies under the umbrella of eHealth. The search terms used in this review are described in Textbox 1 .

The search was first performed in June 2019 and included publications from January 2014 to June 2019. Articles that were more than 5 years old were considered less likely to be 
informative of the present situation as, in general, eHealth and technology are evolving at a rapid pace; this produced an initial publication count of 1624 studies for review. A second iteration of this search was performed in December 2019 to include articles published since June 2019, and this produced 109 additional studies, resulting in an updated initial publication count of 1733 studies. Only articles published in English and French were included in this review.

Textbox 1. Keywords used for database searches.

(santé connectée OR m-santé OR santé numérique OR santé digitale OR e-santé OR internet santé OR digital health OR ehealth OR e-health OR drug reference* OR Medscape OR Epocrates OR UpToDate OR medical domotic* OR mhealth app OR mhealth apps OR mhealth OR mhealth device* OR smart health device* OR connected health device* OR smart health apps OR mobile health app OR mobile health apps OR medical app OR medical apps OR smart medical device* OR connected health OR connected medical apps OR connected medical app OR mobile medical app OR mobile medical apps OR connected health app OR connected health apps OR connected medical device* OR m-health OR m-health app OR m-health apps OR m-health device* OR mobile health device* OR mobile health app OR mobile health apps OR smart apps OR smart app OR internet of things OR iot OR ai OR artificial intelligence OR deep learning OR machine learning OR appjam OR app jam OR ia OR intelligence artificielle OR apprentissage profond OR apprentissage machine OR appli* médicale* OR app* médicale* OR lanthier) AND (medstudent* OR med student* OR medical student* OR future doctor* OR future physician* OR curriculum* OR externe* OR externat OR étudiant* en médecine OR medschool OR medical school OR faculté* de médecine OR programme* de médecine OR étude* en médecine OR formation* médicale* OR formation* en médecine)

\section{Study Selection}

Following the removal of duplicates from the initial publication count, inclusion and exclusion criteria (Textbox 2) were applied during the study selection process, which was divided into 2 main phases.

In the first phase, after the removal of duplicates, each of the 1451 remaining articles was reviewed by 1 of the 3 authors (JE, $\mathrm{FM}$, and $\mathrm{HN}$ ), initially excluding articles if the title and abstract were not related to training in eHealth or to medical students. Full texts were read by JE, FM, or HN when the title and abstract were insufficient to include or exclude a given study. The first author (JE) subsequently screened all studies labeled as included using the finalized inclusion and exclusion criteria. This resulted in the selection of 16 studies, including both previously described iterations of the search.

In the second phase, we conducted a backward and forward reference search on the 16 articles selected in the first phase. All 746 newly obtained references were subjected to the same selection process as in the first phase using the same inclusion and exclusion criteria. Nine additional studies were added at the end of this process, including both iterations of the search.

Thus, the final count of studies included in this scoping review was 25. Throughout this whole process, one author (MP) assessed each phase to ensure and verify the accuracy of the work and contributed to the analysis of results.

Textbox 2. Inclusion and exclusion criteria used for study selection.

Inclusion criteria

- $\quad$ Related to training in eHealth

- $\quad$ Related to the training of medical students. When a study population was not limited to medical students, only data exclusive to medical students were included in this review

Exclusion criteria

- $\quad$ Limited to e-learning of subjects other than eHealth

- Not supported by empirical data, obtained either directly or through a literature review

- Interns, residents, and doctors were not considered medical students as they had already obtained their medical degrees and finished most of their curriculum

- $\quad$ Not published in a peer-reviewed journal

- Published in a language other than English or French

- No access to the full article

\section{Charting Data (Data Extraction)}

We created and used a data extraction grid on a spreadsheet to chart the data from the included studies into different categories including study characteristics, target population, intervention characteristics, data regarding various aspects of eHealth, and other statements regarding the goal of this review (Multimedia Appendix 2). Throughout the charting process, we iteratively revised the extraction grid to refine its components.

\section{Collating, Summarizing, and Reporting the Results}

Results regarding the methodology were thematically subdivided into paragraphs supported by tables as well as figures produced using Microsoft Excel. Findings from included articles were deemed relevant in light of the goals of this review. These relevant findings are presented in the form of tables as we aimed to present an overview of the findings without weighing or aggregating these results. Data regarding methodological characteristics and data regarding relevant findings were not aggregated in a single table because the size of such a table 
would have hindered readability and interpretability. Critical appraisal of included articles and the assessment of the robustness and generalizability of the findings were not performed for this review.

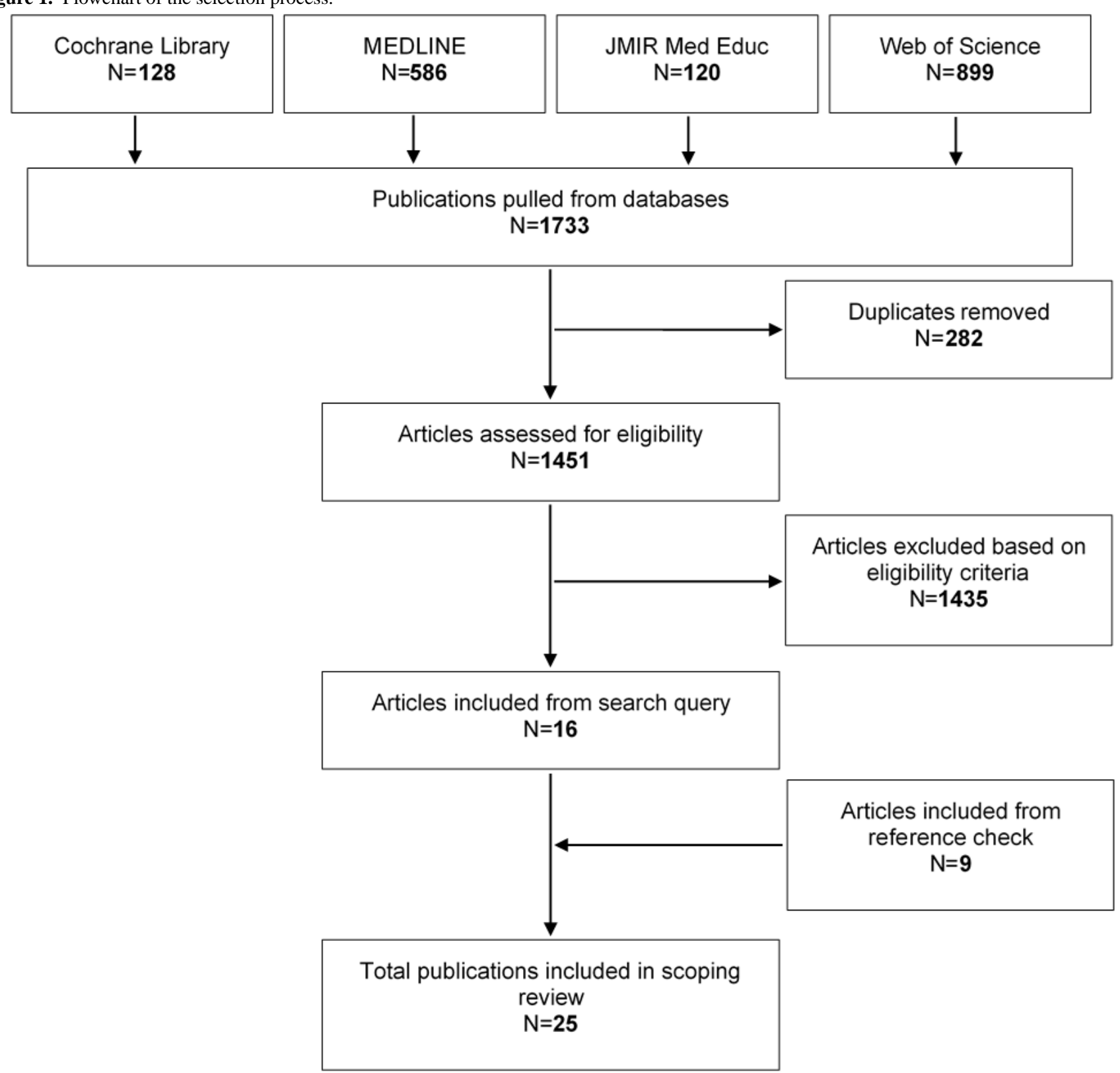

\section{Characteristics of Included Studies}

Included studies were published every year from 2014 to 2019. Notably, nearly half $(12 / 25,48 \%)$ were published in 2019. Studies were categorized as Intervention $(13 / 25,52 \%)$ or No Intervention $(12 / 25,48 \%)$ depending on whether they included

\section{Results}

\section{Selection Process}

A total of 25 articles were included in this scoping review. The selection process of these articles is detailed in Figure 1, and their characteristics are summarized in Multimedia Appendix 3 [14-38]

Figure 1. Flowchart of the selection process 
Figure 2. Number of included articles by year of publication and presence of an intervention.

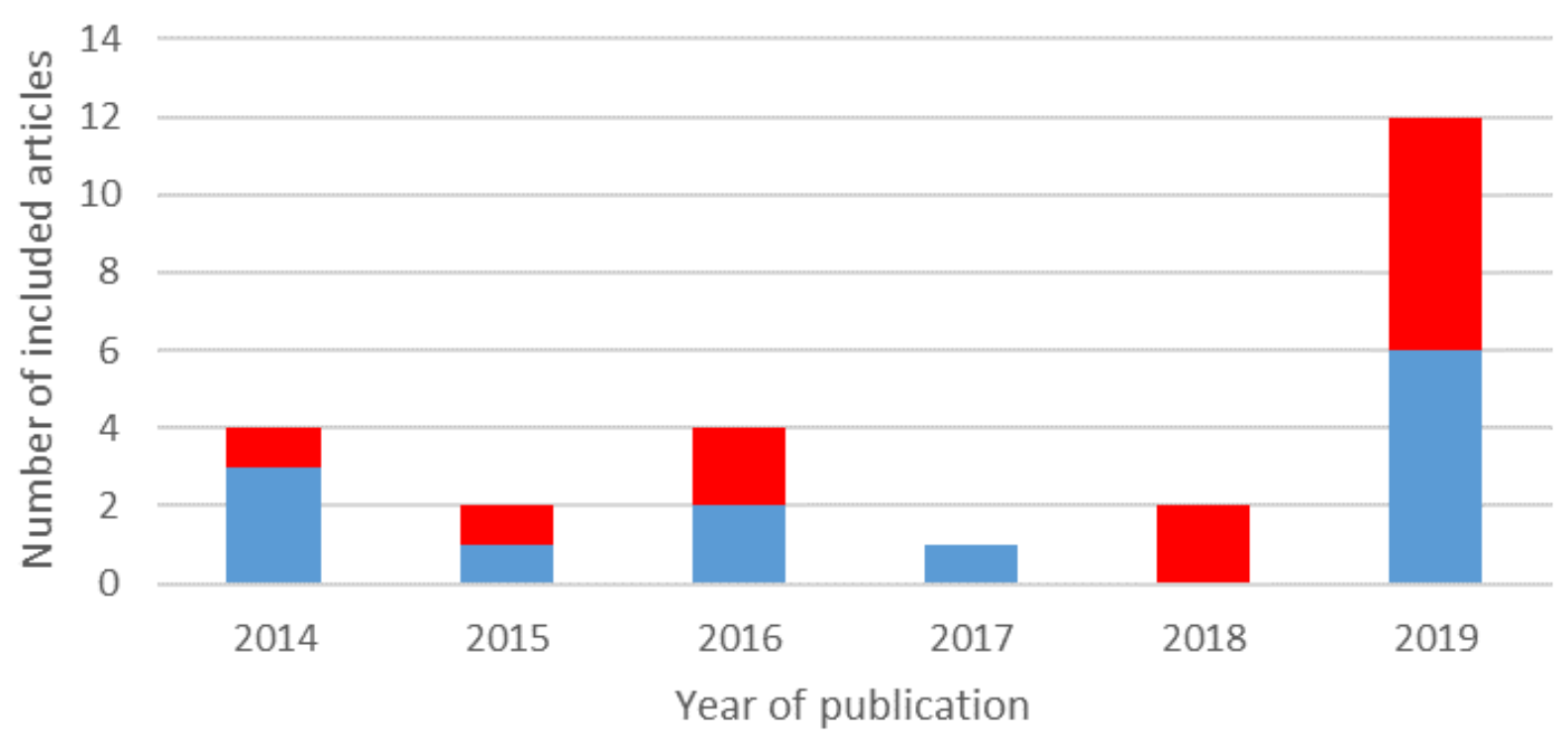

Intervention $\mathbf{a}$ No intervention

Figure 3. Number of articles discussing each aspect of eHealth. AI: artificial intelligence; IoT: internet of things.

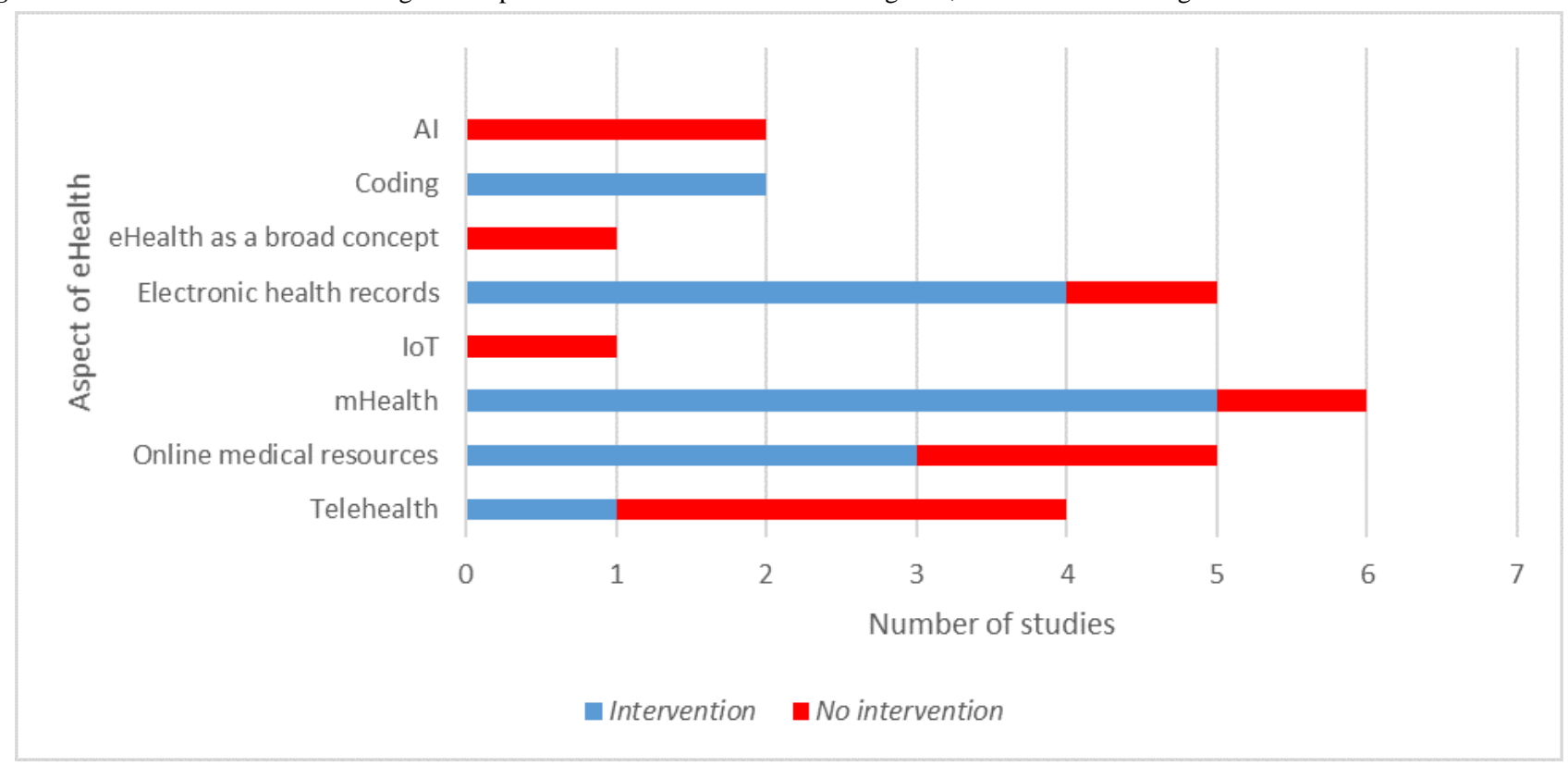

Of the 20 papers that studied a population of medical students, $11(55 \%)$ had a sample size of more than 100 . The smallest study had 9 respondents, and the largest had a population of 17,202 . Only half of the studies specified the student's gender distribution; overall, 55.82\% (623/1116) of students whose gender was specified were female. A total of 4 of the included articles had a study population composed of medical school deans, program directors, faculty members, or similarly involved personnel instead of medical students.

Of the studies that did not include an intervention, most consisted of surveys answered by medical students or faculty members. One study was a mixed methods review that complemented a search of the existing literature with interviews conducted with the administration or faculty members of medical schools that included telemedicine in their curricula. Only 1 No Intervention study was a pure literature review. Among all the included articles, a few contained quantitative data only $(5 / 25,20 \%)$ or qualitative data only $(6 / 25,24 \%)$ and the majority were conducted with a mixed methodology with both types of data $(14 / 25,56 \%)$. The included studies were published in 17 different journals, with JMIR Medical Education (4/25, 16\%), Academic Medicine (4/25, 16\%), the Journal of Telemedicine and Telecare $(2 / 25,8 \%)$, and Medical Teacher $(2 / 25,8 \%)$ being represented more than once.

Studies were conducted in 12 different countries, with the United States being the most represented. Multiple studies have also 
been conducted in Canada, Australia, and Germany. The study locations are displayed in Table 1. No included studies were conducted in South America.

Of the 25 included studies, $10(40 \%)$ did not state their sources of funding, if any. Only 4\% (1/25) study was funded by a private

Table 1. Number of studies by study location.

\begin{tabular}{ll}
\hline Country & Value, $\mathrm{n}(\%)$ \\
\hline United States & $10(40)$ \\
Canada & $3(12)$ \\
Australia & $2(8)$ \\
Germany & $2(8)$ \\
France & $1(4)$ \\
Oman & $1(4)$ \\
Russia & $1(4)$ \\
Rwanda & $1(4)$ \\
Singapore & $1(4)$ \\
Turkey & $1(4)$ \\
United Kingdom & $1(4)$ \\
Zimbabwe & $1(4)$
\end{tabular}

\section{Interventions and Main Findings}

Of the studies that described an intervention, most measured its effect by assessing the students' self-reported confidence in using eHealth. Three used more objective methods, either examination results or faculty observation during simulated patient sessions. None of the included articles sought to demonstrate that the eHealth training of medical students objectively influenced care in nonsimulated environments. Most intervention studies provided medical students with training and information on eHealth, although only 2 did not. Three company, the Western Connecticut Health Network. Another received free UpToDate subscriptions from Wolters Kluwer, but no monetary funding from the company. Moreover, 32\% $(8 / 25)$ explicitly stated that they were not funded, $12 \%(3 / 25)$ were funded by academic institutions, and 12\% (3/25) were financed by public American funding agencies. studies further provided hardware to medical students, and another provided access to a web-based medical resource. Table 2 contains a summary of all the interventions from the included articles, along with the most relevant findings regarding these interventions. The main findings relevant to this review's research question for all No Intervention articles are presented in Table 3. A summary of the characteristics of all included articles is presented in Multimedia Appendix 3 [14-38], including authors, study location, year of publication, and which aspect of eHealth had been studied. 
Table 2. Summary of all interventions from the included articles and related findings.

\begin{tabular}{|c|c|c|}
\hline No. & Aspect of eHealth: aim of the study & Intervention and related findings \\
\hline 1 & $\begin{array}{l}\text { mHealth }{ }^{\mathrm{a}} \text { : to determine whether } \\
\text { providing students with preloaded } \\
\text { iPad Minis would enhance their ex- } \\
\text { perience and increase awareness of } \\
\text { and access to mHealth information } \\
\text { resources for clinical care in a rural } \\
\text { environment }\end{array}$ & $\begin{array}{l}\text { - Tablets preloaded with health apps were given to third-year students, who were also asked to } \\
\text { complete surveys and a journal } \\
\text { - An overall positive value for participants who "accessed essential clinical information, experienced } \\
\text { improved patient education interactions, and accessed tools and resources to assist them in their } \\
\text { experiences" } \\
\text { - Lessons were learned regarding the project } \\
\text { - A clerkship director's request has been made to integrate the project beyond the original pilot }\end{array}$ \\
\hline 2 & $\begin{array}{l}\text { Web-based medical resources: to } \\
\text { describe the effect of the integration } \\
\text { of the OMIM }{ }^{\mathrm{b}} \text { database during the } \\
\text { first year of medical school }\end{array}$ & $\begin{array}{l}\text { - The OMIM database was taught to students who later performed self-assessments of short-term } \\
\text { and long-term learning } \\
\text { - Students' confidence in clinical genetics skills increased after the OMIM education session } \\
\text { - Acknowledging and incorporating students' search preferences can engage them in the importance } \\
\text { of identifying appropriate resources }\end{array}$ \\
\hline
\end{tabular}

3 Programming: to determine whether it is possible to teach medical students the basics of programming in 2 days and whether students value programming and its teaching in medical school

4 Programming: to describe a new elective computing course and discuss how it prepares medical students to use computer science and technology

EHRs ${ }^{c}$ : to develop a course module and evaluate it to identify and share best practices and strategies
- The Coding for Medics course was developed. After 2 days of intensive teaching, participants were given a few weeks to submit a project

- Basics of programming successfully taught in 2 days

- Programming teaching should be offered but optional, "practical" and "relevant to clinical problems"

- Computational thinking learned and considered "transferable"

- Programming valued as an important skill for the future and oversubscribed because of enthusiasm

- Programming deemed necessary for the development of eHealth technologies

- A 14-month Computing for Medicine certificate course (C4M) was developed in collaboration with the Department of Computer Science, University of Toronto. The C4M included workshops, seminars, and a project

- $\quad$ Reinforced valuing and understanding of technology

- Programming and algorithmic and logical thinking skills were taught

- Medical schools should consider computer literacy as an essential skill to enhance engagement with technology, collaboration with developers, and patient care quality

- Questions raised about broader adoption of learn-to-code programs, whether elective or mandatory

- Mandatory participation in EHR full-day intensive training over 2 days for fifth-year students within their seminar in internal medicine

- $\quad$ Positive attitude toward EHR usage and software

- Higher perceived benefits of EHR for doctors and nurses than for other professionals or patients

- Low perceived benefits of EHR for coworking in multiprofessional team

- Documentation is a core competency

- More training, standardized examination, and awareness regarding EHR are needed

Online medical resources: to verify the hypothesis that removing the subscription cost barrier to accessing EBCRs ${ }^{d}$ will lead to high student uptake and to an improvement in educational outcomes

7 mHealth: to allow students to acquire and develop skills using devices and health apps in a clinical context

8 Telehealth and mHealth: to deliver orthopedics education through a mobile app, MyDoc, although teaching medical students about secure communication and the Personal Data Protection Act of Singapore
- Agreement with Wolters Kluwer to facilitate the donations of UpToDate subscriptions to students

- Access to devices and the internet is not a barrier

- The focus should be on web-based tools and evidence

- Higher use of EBCRs when cost barrier removed

- Lower UpToDate uptake by preclinical students

- The introduction of EBCRs during the last year of medical school may lead to habit formation

- Improvement in examination performance of this graduating class

- Equitable access to information is required

- A single-semester elective option, "Computer Games and Applications for Health and Well-being," was introduced for first-year students

- $\quad$ Students not as adept at using mHealth devices as the literature had predicted

- Ownership of a suitable mobile device was lacking

- Availability of useful, free apps was limited

- Key lessons were learned, which we wish will help prepare the medical curriculum

Third-year students were asked to use the MyDoc mobile app that allowed communication in the form of personal messages, case discussions, and sharing of patient details with peers

- Excellent acceptance and satisfaction

- Technical issues needed to be addressed

- There was a need for compliance with privacy laws in the context of the growth of telehealth, so medical schools should consider integrating this secure communication tool to their training 
No. Aspect of eHealth: aim of the study Intervention and related findings

9 Online medical resources: to analyze the effectiveness of a new EBM $\mathrm{OSCE}^{\mathrm{e}}$ for the end of third-year students

- In this OSCE, students were provided with computer stations and performed online searches to answer a standardized patient's questions

- An average of 4 search tools were used

- Most commonly used websites were UpToDate and Google

- Most students successfully provided the patient with relevant evidence

- This new OSCE allowed proper assessment of student EBM skill

10 EHRs: to verify the hypothesis that an educational intervention for second-year students improves their ability to use the EHR in a way that enhances patient-provider interaction (EHR ergonomics) during a SP ${ }^{\mathrm{f}}$ encounter

11 mHealth: to determine whether medical students, with little or no prior knowledge or training in app development, can use development tools to develop useful health apps

12 mHealth: to determine the ways by which third-year students used mobile technology for learning and clinical decision support

13 EHRs: to address a training gap by describing the $\mathrm{Sim}^{\mathrm{g}}$-EHR curriculum and sharing participant feedback and lessons learned
- EHR ergonomic training's impact on patient-provider interaction during SP encounters was compared with the impact of basic EHR training with no additional EHR ergonomic training

- $\quad$ EHR use improved with EHR ergonomic training

- Students felt improvement in engaging the patients, articulating EHR use benefits, addressing patient concerns, positioning EHR device, and integrating EHR in patient encounter

- A minimum of 3 ergonomic training sessions were necessary to see overall improvement

- Self-perceptions were consistent with performance as observed by SPs and faculty members

- Medical students were taught the fundamentals of health app design and development and asked to use the iBuildApp environment to develop an app

- $\quad$ Perceived need for such training increased

- Previous programming experience was the strongest influencer of a positive experience

- It is possible to teach medical students the fundamentals of app design so that they may contribute to health app development

- Students were provided an iPad and information was collected with beginning and end-of-year questionnaires, iPad usage logs, weekly rounding observations, and weekly semistructured student interviews over a 12-month period

- Tablet computers used to enhance patient care and learning in clinical contexts

- Data service capability and midlevel storage capacity should be provided on each device

- Quarterly app training should be integrated to increase effectiveness in clinical decision support

- The Sim-EHR curriculum, consisting of simulated charts for virtual patients, was implanted as part of the third-year family medicine clerkship

- Increased comfort with finding information, inputting orders, and updating a health maintenance tool

- Recognition of the value of the activity

- Expressed frustrations with timing and opportunity costs

- Improved ability to place orders and update chart

- No difference in ability to use a health maintenance tool to create routine disease screening, prevention, and management alerts

\footnotetext{
${ }^{\mathrm{a}} \mathrm{mH}$ ealth: mobile health.

${ }^{b}$ OMIM: Online Mendelian Inheritance in Man.

${ }^{\mathrm{c}}$ EHR: electronic health record.

${ }^{\mathrm{d}}$ EBCR: evidence-based clinical resources.
}

${ }^{\mathrm{e}}$ EBM OSCE: Evidence-Based Medicine Objective Structured Clinical Examination.

${ }^{\mathrm{f}} \mathrm{SP}$ : standardized patient.

${ }^{\mathrm{g}} \mathrm{Sim}$ : simulated. 
Table 3. Summary of the main findings regarding medical students' training in eHealth for articles that did not contain interventions.

\begin{tabular}{lll}
\hline No. & Aspect of eHealth: aim of the study & Main findings \\
\hline 14 & $\begin{array}{l}\mathrm{AI}^{\mathrm{a}} \text { : to examine medical students' } \\
\text { perceptions of the impact of AI on }\end{array}$ & - Students believed education on AI is important \\
$\begin{array}{l}\text { radiology, contributing factors, and } \\
\text { influence on their choice of special- }\end{array}$ & - Students recommended inviting experts \\
ty & - AI was not mentioned in the curriculum \\
& - AI courses and projects were equally effective as formal computer science education
\end{tabular}

$15 \quad$ AI: to assess medical students' feelings on $\mathrm{AI}$ in radiology and medicine and to evaluate whether they were worried about AI replacing radiologists and other physicians

16 Telehealth: to describe telemedicine education and training implementation and to evaluate the knowledge, attitudes, and practices of deans and associate deans

17 Telehealth: to analyze the legal, economic, and research-related factors associated with the implementation of telemedicine programs in various countries

$18 \quad$ IoT $^{\mathrm{b}}$ : to determine future health professionals' opinions regarding trends in health-related technology, to determine their readiness to use health technologies, and to identify the use of IoT technology in medical applications

19 eHealth as a broad concept: to explore the progress of eHealth training according to curriculum staff and decision makers from all 19 Australian medical schools

20 EHRs $s^{\mathrm{c}}$ : to examine student accounts of EHR use during a time period in which implementation of EHR systems dramatically increased

21 mHealth ${ }^{\mathrm{d}}$ : to better understand the experiences in implementing mobile technology initiatives during the clinical years of undergraduate medical education

22 Web-based medical resources: to examine access, attitude, and training regarding use of electronic resources and $\mathrm{EBM}^{\mathrm{e}}$ by students after the implementation of the MEPI ${ }^{\mathrm{f}}$
- Students want AI and deep learning to be incorporated into medical curricula

- Students need better understanding of deep learning and AI, as well as knowledge of "what data are needed for which type of tasks" and "how AI algorithms should be evaluated"

- Training will maybe compensate for the tendency of males and more tech-savvy respondents to be more confident, less concerned, and more interested in AI being taught

Telemedicine training implementation was limited compared with mandatory legislation

- Most respondents expressed a positive attitude toward telemedicine and its potential threats to present medical practices

- Barriers such as lack of knowledge, resources, support, practice, and funding in telemedicine were identified

- Student training in eHealth was one of the factors associated with higher odds of implemented teleradiology and telepathology

- The average scholarly output related to telemedicine was much higher in countries with versus without training of health care providers

- Most had no knowledge on the IoT and did not follow publications regarding the IoT

- Most stated that IoT will affect health, education, genetic and data security, and medical and nursing practices, and that IoT can be used in smart patient follow-ups and mobile health apps

- Opinions regarding the future of IoT should focus on vital follow-up (blood glucose and electrocardiogram), wearables, and chronic diseases

- Not aware of the effects of robots or cannot imagine robotic health professionals

- All participants knew about eHealth

- No formal eHealth training programs had been established

- Informal training and experiential learning during clinical placements were acknowledged

- eHealth training was considered "important, but not important enough"

- There were competing curricular priorities, a lack of dialogue with the health system, and no strong drivers for change

- The situation was unlikely to change until accrediting bodies expect competence in eHealth

- Students used EHRs in the majority of their clerkships; this use increased from 2012 to 2016

- Increase in student entry of information into EHRs

- Decrease in mean percentage of clerkships in which students entered orders

- Decrease in student use of paper health records

- Need to incorporate EHR training into medical school curricula to ensure patient safety and care

- Eight best practices for introducing mobile technology in the clinical years were identified: plan before implementation, define focused goals, establish a tablet culture, recruit an appropriate implementation team, invest in training, involve students in mentoring, accept variable use, and encourage innovation

- Most did not receive formal training in EBM

- Most who received formal training in EBM found it inadequate

- Most who did not receive formal training wished to receive EBM training

- Most did not receive formal training in journal club presentation and scientific reading skills, among which most showed interest in learning these skills

- Most felt more or less confident in their capabilities of distinguishing the value of medical literature with only $8 \%(5 / 61)$ feeling extremely secure

- Training required on evaluating sources

- Inadequate training regarding access to medical literature and information; need to do better 


\begin{tabular}{|c|c|c|}
\hline No. & Aspect of eHealth: aim of the study & Main findings \\
\hline 23 & $\begin{array}{l}\text { Online medical resources: to de- } \\
\text { scribe medical students' behavior } \\
\text { and training regarding information } \\
\text { search and evidence appraisal }\end{array}$ & 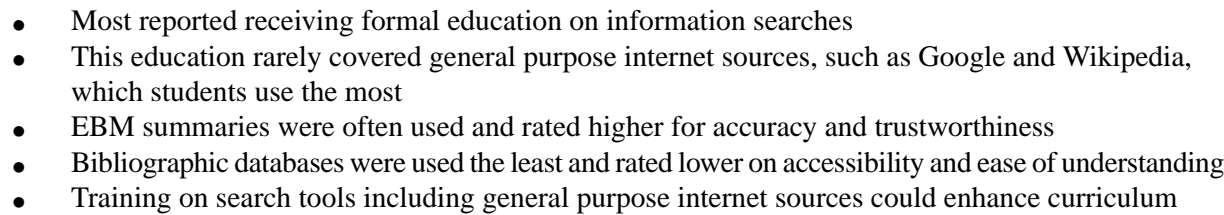 \\
\hline
\end{tabular}

24 EHRs: to determine the amount of time the student spent on EHR use and the potential benefits of student EHR use on education outcomes
- Students on the Internal Medicine rotation logged more hours per day on the EHR than students in other clerkships

- Low EHR use in Obstetrics and Gynecology, Neurology, and General Surgery

- EHR activity during the Internal Medicine rotation corresponded to half of an average workday

- No association between self-reported and observed EHR use

- $\quad$ No correlation between EHR use and patient care based on examinations

25 Telehealth: to characterize medical schools' approaches for implementing telemedicine training (mixed methods review)
The diverse approaches were a promising sign of accelerating growth in this domain

- Future effort needed on the part of institutions to make training meaningful and comprehensive

- Concerns included telemedicine's inclusion in the curriculum being cursory or not meaningful

\footnotetext{
${ }^{\mathrm{a}} \mathrm{AI}$ : artificial intelligence.

${ }^{\mathrm{b}}$ Iot: internet of things.

${ }^{\mathrm{c}}$ EHR: electronic health record.

$\mathrm{d}_{\text {mHealth: mobile health. }}$

${ }^{\mathrm{e}}$ EBM: evidence-based medicine.

${ }^{\mathrm{f}}$ MEPI: Medical Education and Partnership Initiative.
}

\section{Discussion}

\section{Overview of the Literature}

This review aimed to evaluate the extent and nature of the existing literature on medical student training in eHealth, while examining what this education consists of, the barriers, enhancing factors, and propositions for improving medical curriculum. This review focuses primarily on key technologies such as mHealth, the IoT, telehealth, and AI. An overview of the literature is discussed in this subsection.

The most studied aspects of eHealth were mHealth, web-based medical resources, electronic health records (EHRs), and telehealth, while eHealth as a broad concept, the IoT, AI, and programming were the least studied aspects. The marked increase in the number of publications on eHealth and medical students in 2019 (6 times more than the previous year) indicates that a greater amount of research has been conducted in the last few years and is likely to signal a larger number of publications in the next few years.

A total of $52 \%(13 / 25)$ of the included articles contained an intervention. Some aspects of eHealth were mostly studied through an intervention; this was the case for mHealth, EHRs, web-based medical resources, and programming. On the contrary, no interventions were part of the methodology of most studies regarding telehealth, AI, the IoT, and eHealth as a broad concept. These results might indicate that some aspects of eHealth are easier to examine or best studied through interventions while others are not. For instance, the IoT and AI were only covered through surveys without any interventions, perhaps because it would be difficult to build a practical yet realistic training program regarding these topics. Programming for medical students was examined through studies containing interventions, which could be attributed to its arguably greater potential for hands-on training (eg, by asking students to develop a simple program) compared with other technologies. Overall, the study population consisted of slightly more females than males, in accordance with the gender distribution of medical students in western countries such as the United States and the United Kingdom [39,40].

\section{Barriers, Enhancing Factors, and Propositions}

The findings of the included studies comprehended barriers, enhancing factors, and propositions for improving medical training in eHealth and may also help researchers formulate other hypotheses on the subject. Identified barriers include competing for curricular priorities, lack of dialogue with the health care system, no strong drivers for change, technical issues (eg, internet access), and limited availability of useful, free items. Enhancing factors include student characteristics (eg, tech-savviness), students' interest, careful planning, and goal setting. Propositions include implementing new courses and rotations, inviting experts to medical schools, planning better before implementation, mentoring by students, and investing resources.

As there are probably many more barriers, enhancing factors, and propositions that have not been described in the extant literature, we recommend that additional studies be conducted to better identify themes for eHealth as a broad concept as well as for each technology.

\section{Gaps in the Literature}

No study has examined the impact of eHealth training on real health care outcomes, probably because measuring this would be too complicated, long, costly, and subject to many confounding and modulating variables. Only 2 studies directly observed clinical skills related to eHealth, although both times 
through simulated, standardized patients. These 2 articles evaluated medical student performances with web-based medical resources and EHRs. We therefore recommend that researchers evaluate both learning outcomes and patient care outcomes from training in eHealth.

Less data have also been collected about competencies that future doctors should develop to be ready for medicine that is increasingly digitalized. Therefore, we recommend conducting studies about what knowledge, abilities, and competencies medical students should acquire both in their preclinical and clinical forms.
Stakeholders would especially benefit from a significant increase in the literature on the IoT and AI, although we recommend that additional studies should be conducted regarding eHealth as a broad concept as well as regarding all related technologies.

Our recommendations are detailed in Table 4 in the form of research topics and specific aspects. No specific methodologies for future studies are recommended, but a diversity of study types would probably best enhance the literature. Studies either containing an intervention or not would be relevant. 
Table 4. Recommendations in the form of research topics and specific aspects.

\begin{tabular}{|c|c|}
\hline Research topics & Specific aspects \\
\hline $\begin{array}{l}\text { What is the current state of training in eHealth? } \\
\text { (notably regarding the internet of things) }\end{array}$ & $\begin{array}{ll}\text { - } & \text { Optimal training } \\
\text { - } & \text { Suboptimal training } \\
\text { - } & \text { Little to no training } \\
\text { - } & \text { Theory versus practical } \\
\text { - } & \text { Preclinical versus clinical } \\
\text { - } & \text { Optional versus mandatory }\end{array}$ \\
\hline What are the barriers to training in eHealth? & $\begin{array}{ll}\text { - } & \text { Student characteristics (eg, age, prior education) } \\
\text { - } & \text { Competing curricular priorities } \\
\text { - } & \text { Lack of dialogue with the health care system } \\
\text { - } & \text { No strong drivers for change } \\
\text { - } & \text { Lack of interest } \\
\text { - } & \text { Technical issues (eg, internet access) } \\
\text { - } & \text { Limited availability of useful, free items }\end{array}$ \\
\hline $\begin{array}{l}\text { What are the enhancing factors for training in } \\
\text { eHealth? }\end{array}$ & $\begin{array}{ll}\text { - } & \text { Student characteristics (eg, age, prior education) } \\
\text { - } & \text { Perceived relevance } \\
\text { - } & \text { Students' interest } \\
\text { - } & \text { Medical school personnel's interest } \\
\text { - } & \text { Governments and leaders' interest } \\
\text { - } & \text { Medical associations' interest } \\
\text { - } & \text { Strong drivers for change }\end{array}$ \\
\hline
\end{tabular}

- Strong drivers for change

What could be done to enhance training in eHealth?
What are the competencies and skills in eHealth that medical students want or should acquire?
What is the impact of the implementation of an initiative such as a special course or a special rotation related to eHealth?
Increasing interest of students, medical school personnel, governments, leaders, and medical associations

- Increasing requirements by accrediting bodies

- Implementation of new courses

- Implementation of new rotations

- Inviting experts to medical schools

- $\quad$ Planning ahead (eg, anticipating technical issues)

- Mentoring (by students, residents, and doctors, etc)

- Investing resources such as funding

- Knowledge of basic principles

- Science, technology, engineering, and mathematics

- Data for surveillance, planning, and managing of scarce resources

- Data visualization, analysis, quality assessment, and governance

- $\quad$ eHealth applied to public health and preventive medicine

- Confidentiality and risks associated with data collection and communication

- Critical appraisal

- $\quad$ Technical skills (eg, programming)

- Cognitive aspects (eg, computational thinking)

- Interdisciplinary collaboration

- Communication

- $\quad$ Ethics and legal aspects

- Learning outcomes

- Patient care outcomes

- Students' appreciation

- Costs

- $\quad$ Best if optional versus if mandatory

How is ehealth training discussed in non-peer-reviewed publications?

- Broader discussion of this topic

- Data, perspectives, information that might differ from peer-reviewed articles

- Most of the specific aspects for other research topics listed above apply

\section{Limitations}

The results of this scoping review are subject to limitations. Articles published before 2014 that might nonetheless have retained relevance were excluded from this review. Conversely, the pressure on medical schools to implement new eHealth training could be so important that even some of the recently
eHealth differ between authors, this review's scope might also be considered too narrow and therefore exclude relevant technologies, while the unequal number of keywords used for each technology in the initial search might have resulted in increased sensitivity for some aspects of eHealth, such as mHealth. In the same vein, terms such as health/medical/clinical 
informatics could have yielded more relevant articles on eHealth as a broad concept. In addition, including search terms related to EHRs could have yielded more studies on this aspect of eHealth, which would perhaps have allowed for a more detailed overview of medical student training in EHRs and best practices in this area. Overall, the choice of key terms searched has driven the outcome of this review. Furthermore, no hand-searching of printed sources was performed; however, all recent relevant articles on eHealth were assumed to be indexed on the web. Articles from JMIR Medical Education could be overrepresented because this journal's database was used in this review's study selection process. The selection of databases has probably driven the results of this review overall, but this decision is supported by the relevant results of our preliminary search on these databases as well as their characteristics. Other databases could have been considered including the Education Resources Information Center, which is more focused on education, although it could be considered less specific for medical topics. Similarly, searching the gray literature would have yielded different articles, but the scope of this review is limited to peer-reviewed articles. Finally, the generalizability of our findings might be limited for medical schools in countries not represented among the included articles.

\section{Conclusions}

This review highlights relevant research findings regarding medical student training in eHealth from 25 included articles.
Although a definite assessment of the state of medical education in eHealth cannot be inferred from the extant literature, trends have emerged from the included studies regarding the suboptimal current state of eHealth training and the barriers, enhancing factors, and propositions for optimal training of medical students. We recommend additional studies on these themes, but also on what knowledge, abilities, and competencies medical students should acquire at the preclinical and clinical stages of their undergraduate education. Additional studies should be conducted on eHealth and each of the many technologies it comprehends, but more research is especially needed regarding the IoT, AI, programming, and eHealth as a broad concept. We also recommend that researchers evaluate both learning and patient care outcomes from training in eHealth.

The training of medical students in eHealth is critical to their future practice in clinical environments that is increasingly enabled by technology. There is room for improvement in this regard, which will require meaningful changes to their curricula and learning opportunities. How the challenge of medical student training in eHealth will be met will most likely have a significant impact on health care in the near future. The COVID-19 pandemic highlights the relevance of eHealth training as the need for innovative approaches to health care presents itself both as an opportunity and as a challenge.

\section{Acknowledgments}

All authors contributed to this study, and their respective contributions are detailed in the Methods section of this paper.

This project was funded by the Evaluation Program of State-of-the-Art Technology and Methods: Citizen and patient engagement in the transformation of health organizations and institutions (Centre de recherche du Centre hospitalier de l'Université de Montréal-Fonds de la recherche du Québec-Santé- Ministère de la santé et des services sociaux du Québec). The authors have no other financial disclosure.

\section{Conflicts of Interest}

None declared.

\section{Multimedia Appendix 1}

Glossary.

[DOCX File , 22 KB-Multimedia Appendix 1]

\section{Multimedia Appendix 2}

Components of the data extraction grid.

[DOCX File , 22 KB-Multimedia Appendix 2]

\section{Multimedia Appendix 3}

Summary of characteristics of included studies. [DOCX File , 26 KB-Multimedia Appendix 3]

\section{References}

1. Virtual Care. Canadian Medical Association. 2019. URL: https://www.cma.ca/virtual-care [accessed 2020-01-31]

2. Speyer R, Denman D, Wilkes-Gillan S, Chen Y, Bogaardt H, Kim J, et al. Effects of telehealth by allied health professionals and nurses in rural and remote areas: a systematic review and meta-analysis. J Rehabil Med 2018 Feb 28;50(3):225-235 [FREE Full text] [doi: 10.2340/16501977-2297] [Medline: 29257195] 
3. So CF, Chung JW. Telehealth for diabetes self-management in primary healthcare: a systematic review and meta-analysis. J Telemed Telecare 2018 Jun;24(5):356-364. [doi: 10.1177/1357633X17700552] [Medline: 28463033]

4. Xiao Q, Wang J, Chiang V, Choi T, Wang Y, Sun L, et al. Effectiveness of mhealth interventions for asthma self-management: a systematic review and meta-analysis. Stud Health Technol Inform 2018;250:144-145. [Medline: 29857410]

5. Nindrea RD, Aryandono T, Lazuardi L, Dwiprahasto I. Diagnostic accuracy of different machine learning algorithms for breast cancer risk calculation: a meta-analysis. Asian Pac J Cancer Prev 2018 Jul 27;19(7):1747-1752 [FREE Full text] [doi: 10.22034/APJCP.2018.19.7.1747] [Medline: 30049182]

6. Lee Y, Ragguett R, Mansur RB, Boutilier JJ, Rosenblat JD, Trevizol A, et al. Applications of machine learning algorithms to predict therapeutic outcomes in depression: a meta-analysis and systematic review. J Affect Disord 2018 Dec 1;241:519-532. [doi: 10.1016/j.jad.2018.08.073] [Medline: 30153635]

7. Meskó B, Drobni Z, Bényei E, Gergely B, Győrffy Z. Digital health is a cultural transformation of traditional healthcare. Mhealth 2017;3:38 [FREE Full text] [doi: 10.21037/mhealth.2017.08.07] [Medline: 29184890]

8. Laupacis A. Working together to contain and manage COVID-19. Can Med Assoc J 2020 Mar 30;192(13):E340-E341 [FREE Full text] [doi: 10.1503/cmaj.200428] [Medline: 32184199]

9. eHealth Competencies for Undergraduate Medical Education. Canada Health Infoway. 2014. URL: https://www. infoway-inforoute.ca/en/component/edocman/3400-ehealth-competencies-for-undergraduate-medical-education/ view-document?Itemid=0 [accessed 2020-01-31]

10. Stratégie Nationale E-santé 2020. Ministère des Solidarités et de la Santé. 2016. URL: https://solidarites-sante.gouv.fr/IMG/ pdf/strategie_e-sante_2020.pdf [accessed 2020-01-31]

11. National E-Health and Information Principal Committee. Australian Government Department of Health. 2008. URL: https:/ /www1.health.gov.au/internet/main/publishing.nsf/Content/69B9E01747B836DCCA257BF0001DC5CC/\$File/ National\%20eHealth\%20Strategy\%20final.pdf [accessed 2020-01-31]

12. National eHealth Strategy Toolkit. World Health Organization. 2012. URL: https://apps.who.int/iris/bitstream/handle/10665/ 75211/9789241548465 eng.pdf;jsessionid=40435BAD08FBA494AD0E80B92FFF26C1?sequence=1 [accessed 2020-01-31]

13. Arksey H, O'Malley L. Scoping studies: towards a methodological framework. Int J Soc 2005 Feb;8(1):19-32. [doi: 10.1080/1364557032000119616]

14. dos Santos DP, Giese D, Brodehl S, Chon SH, Staab W, Kleinert R, et al. Medical students' attitude towards artificial intelligence: a multicentre survey. Eur Radiol 2019 Apr;29(4):1640-1646. [doi: 10.1007/s00330-018-5601-1] [Medline: 29980928]

15. Yaghobian S, Ohannessian R, Mathieu-Fritz A, Moulin T. National survey of telemedicine education and training in medical schools in France. J Telemed Telecare 2020 Jun;26(5):303-308. [doi: 10.1177/1357633X18820374] [Medline: 30602352]

16. Edirippulige S, Brooks P, Carati C, Wade VA, Smith AC, Wickramasinghe S, et al. It's important, but not important enough: eHealth as a curriculum priority in medical education in Australia. J Telemed Telecare 2018 Dec;24(10):697-702. [doi: 10.1177/1357633X18793282] [Medline: 30343657]

17. Deutsch K, Gaines JK, Hill JR, Nuss MA. iPad experience during clinical rotations from seven medical schools in the United States: lessons learned. Med Teach 2016 Nov;38(11):1152-1156. [doi: 10.3109/0142159X.2016.1170778] [Medline: 27117525]

18. O'Carroll AM, Westby EP, Dooley J, Gordon KE. Information-seeking behaviors of medical students: a cross-sectional web-based survey. JMIR Med Educ 2015 Jun 29;1(1):e4 [FREE Full text] [doi: 10.2196/mededu.4267] [Medline: 27731842]

19. Waseh S, Dicker AP. Telemedicine training in undergraduate medical education: mixed-methods review. JMIR Med Educ 2019 Apr 8;5(1):e12515 [FREE Full text] [doi: 10.2196/12515] [Medline: $\underline{\text { 30958269] }}$

20. Johnson EM, Howard C. A library mobile device deployment to enhance the medical student experience in a rural longitudinal integrated clerkship. J Med Libr Assoc 2019 Jan;107(1):30-42 [FREE Full text] [doi: 10.5195/jmla.2019.442] [Medline: 30598646]

21. Lee-Barber J, Kulo V, Lehmann H, Hamosh A, Bodurtha J. Bioinformatics for medical students: a 5-year experience using OMIM in medical student education. Genet Med 2019 Feb;21(2):493-497. [doi: 10.1038/s41436-018-0076-7] [Medline: 29930391]

22. Morton CE, Smith SF, Lwin T, George M, Williams M. Computer programming: should medical students be learning it? JMIR Med Educ 2019 Mar 22;5(1):e11940 [FREE Full text] [doi: 10.2196/11940] [Medline: 30901000]

23. Law M, Veinot P, Campbell J, Craig M, Mylopoulos M. Computing for medicine: can we prepare medical students for the future? Acad Med 2019 Mar;94(3):353-357 [FREE Full text] [doi: 10.1097/ACM.0000000000002521] [Medline: 30431453]

24. Fernando J, Lindley J. Lessons learned from piloting mHealth informatics practice curriculum into a medical elective. J Am Med Inform Assoc 2018 Apr 1;25(4):380-384. [doi: 10.1093/jamia/ocx076] [Medline: 29024956]

25. Daruwalla ZJ, Loh JL, Dong C. Spaced education and the importance of raising awareness of the personal data protection act: a medical student population-based study. JMIR Med Educ 2016 Aug 9;2(2):e12 [FREE Full text] [doi: 10.2196/mededu.5586] [Medline: 27731866]

26. Amini R, Hernandez NC, Keim SM, Gordon PR. Using standardized patients to evaluate medical students' evidence-based medicine skills. J Evid Based Med 2016 Feb;9(1):38-42. [doi: 10.1111/jebm.12183] [Medline: 26646923] 
27. Masters K. Health professionals as mobile content creators: teaching medical students to develop mHealth applications. Med Teach 2014 Oct;36(10):883-889. [doi: 10.3109/0142159X.2014.916783] [Medline: 25072254]

28. Nuss MA, Hill JR, Cervero RM, Gaines JK, Middendorf BF. Real-time use of the iPad by third-year medical students for clinical decision support and learning: a mixed methods study. J Community Hosp Intern Med Perspect 2014;4(4):- [FREE Full text] [doi: 10.3402/jchimp.v4.25184] [Medline: 25317266]

29. Gong B, Nugent JP, Guest W, Parker W, Chang PJ, Khosa F, et al. Influence of artificial intelligence on Canadian medical students' preference for radiology specialty: a national survey study. Acad Radiol 2019 Apr;26(4):566-577. [doi: 10.1016/j.acra.2018.10.007] [Medline: 30424998]

30. Milano CE, Hardman JA, Plesiu A, Rdesinski RE, Biagioli FE. Simulated electronic health record (Sim-EHR) curriculum: teaching EHR skills and use of the EHR for disease management and prevention. Acad Med 2014 Mar;89(3):399-403 [FREE Full text] [doi: 10.1097/ACM.0000000000000149] [Medline: 24448035]

31. Herrmann-Werner A, Holderried M, Loda T, Malek N, Zipfel S, Holderried F. Navigating through electronic health records: survey study on medical students' perspectives in general and with regard to a specific training. JMIR Med Inform 2019 Nov 12;7(4):e12648 [FREE Full text] [doi: 10.2196/12648] [Medline: $\underline{\text { 31714247] }}$

32. Valtis YK, Rosenberg JD, Wachter K, Kisenge R, Mashili F, Chande Mallya R, et al. Better evidence: prospective cohort study assessing the utility of an evidence-based clinical resource at the University of Rwanda. BMJ Open 2019 Aug 8;9(8):e026947 [FREE Full text] [doi: 10.1136/bmjopen-2018-026947] [Medline: 31399450]

33. Silverman H, Ho Y, Kaib S, Ellis WD, Moffitt MP, Chen Q, et al. A novel approach to supporting relationship-centered care through electronic health record ergonomic training in preclerkship medical education. Acad Med 2014 Sep;89(9):1230-1234 [FREE Full text] [doi: 10.1097/ACM.0000000000000297] [Medline: 24826851]

34. Bodur G, Gumus S, Gursoy NG. Perceptions of Turkish health professional students toward the effects of the internet of things (IOT) technology in the future. Nurse Educ Today 2019 Aug;79:98-104. [doi: 10.1016/j.nedt.2019.05.007] [Medline: 31112847]

35. Chi J, Kugler J, Chu IM, Loftus PD, Evans KH, Oskotsky T, et al. Medical students and the electronic health record: 'an epic use of time'. Am J Med 2014 Sep;127(9):891-895. [doi: 10.1016/j.amjmed.2014.05.027] [Medline: 24907594]

36. Foster LM, Cuddy MM, Swanson DB, Holtzman KZ, Hammoud MM, Wallach PM. Medical student use of electronic and paper health records during inpatient clinical clerkships: results of a national longitudinal study. Acad Med 2018 Nov;93(11S Association of American Medical Colleges Learn Serve Lead: Proceedings of the 57th Annual Research in Medical Education Sessions):S14-S20. [doi: 10.1097/ACM.0000000000002376] [Medline: 30365425]

37. Parve S, Ershadi A, Karimov A, Dougherty A, Ndhlovu CE, Chidzonga MM, et al. Access, attitudes and training in information technologies and evidence-based medicine among medical students at University of Zimbabwe College of Health Sciences. Afr Health Sci 2016 Sep;16(3):860-865 [FREE Full text] [doi: 10.4314/ahs.v16i3.29] [Medline: 27917222]

38. Avanesova AA, Shamliyan TA. Worldwide implementation of telemedicine programs in association with research performance and health policy. Health Policy Technol 2019 Jun;8(2):179-191. [doi: 10.1016/j.hlpt.2019.04.001]

39. 2019 FACTS: Applicants and Matriculants Data. Association of American Medical Colleges. 2019. URL: https://www. aamc.org/data-reports/students-residents/interactive-data/2019-facts-applicants-and-matriculants-data [accessed 2019-11-22]

40. The State of Medical Education and Practice in the UK. The General Medical Council (GMC). 2016. URL: https://www. gmc-uk.org/about/what-we-do-and-why/data-and-research/the-state-of-medical-education-and-practice-in-the-uk [accessed 2020-08-24]

\section{Abbreviations}

AI: artificial intelligence

EHR: electronic health record

IoT: internet of things

JMIR: Journal of Medical Internet Research

mHealth: mobile health

Edited by A Shachak; submitted 09.05.20; peer-reviewed by C Gibson, D Sobral; comments to author 03.07.20; revised version received 16.07.20; accepted 17.07.20; published 11.09.20

Please cite as:

Echelard JF, Méthot F, Nguyen HA, Pomey MP

Medical Student Training in eHealth: Scoping Review

JMIR Med Educ 2020;6(2):e20027

URL: https://mededu.jmir.org/2020/2/e20027

doi: $10.2196 / 20027$

PMID: 32915154 
CJean-François Echelard, François Méthot, Hue-Anh Nguyen, Marie-Pascale Pomey. Originally published in JMIR Medical Education (http://mededu.jmir.org), 11.09.2020. This is an open-access article distributed under the terms of the Creative Commons Attribution License (https://creativecommons.org/licenses/by/4.0/), which permits unrestricted use, distribution, and reproduction in any medium, provided the original work, first published in JMIR Medical Education, is properly cited. The complete bibliographic information, a link to the original publication on http://mededu.jmir.org/, as well as this copyright and license information must be included. 